\title{
MASTER
}

WASTE MANAGEMENT PROGRAM

\author{
David 0akley
}

\section{December 1979}

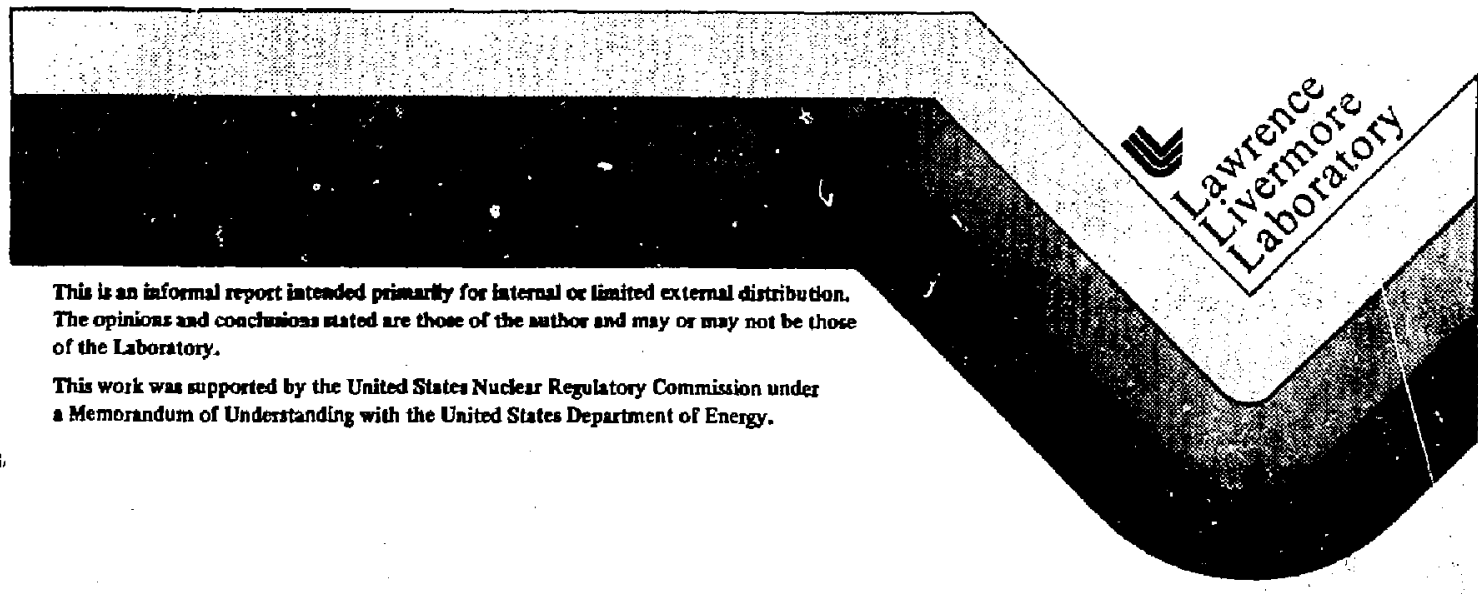

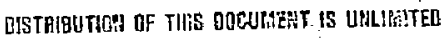


Vecenber 26, 1979

W44 79-445-0

\title{
FOREWORO
}

\begin{abstract}
This report has been prepared as an account of work done during FY 1979 by the Lawrence Livermore Laboratory as a technical assistance task for the Huclear Regulatory Comission under FIf A0277.
\end{abstract}


December 26, 1979

WN 79-445-D

\section{ABSTRACT}

Regulatable elements of a deep geological nuclear waste isolation systern are those characteristics of a candidate systen which need to be specified to achieve control of its performance. This report identifies the regulatable elements with respect to waste form, repository design, site suilability, and the rlodering and decision analysis processes. Regulatable elements in each section are listed and described briefly as they affect the short-teril and lony-terii performance of a deep geological repository. 


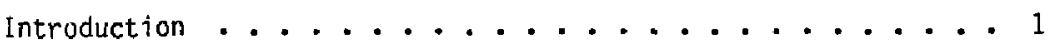

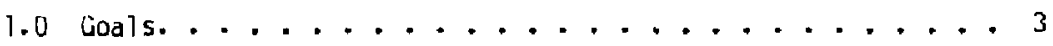

2.0 Regulatable Elements of Haste Farm

Performance ................. 4

2.1 Waste Form ............... 4

2. 1.1 Short-Term Perfori!nce........ 4

2.1.2 Long-Terlil Perfornance ......... . 5

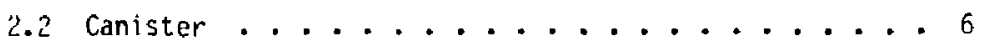

2.2.1 Short-Teria Perforiance . . . . . . . . 6

2.2 .2 Long-Terin Performance . . . . . . . . 6

2.3 Packaging................ 7

2.3.1 Short-Term Performance. . . . . . . . . 7

2.3.2 Long-Teriil Performance . . . . . . . . 7

2.4 Monitoring Requirentents ........... 8

2.4.1 Short-Terim Performance . . . . . . . 9

2.4.2 Long-Terin Performance . . . . . . . 10

3.0 kegulatable Elements of Ropository

Design Performance ................... Il

3.1 Repository Structure and 0peration ........ 11

3.1.1 Short-Teriil Perfornance.......... 11

3.1.2 Long-Term Performance ........... 14

3.2 Repository Containment ............ 15 
TABLL OF CONTEITS (Continued)

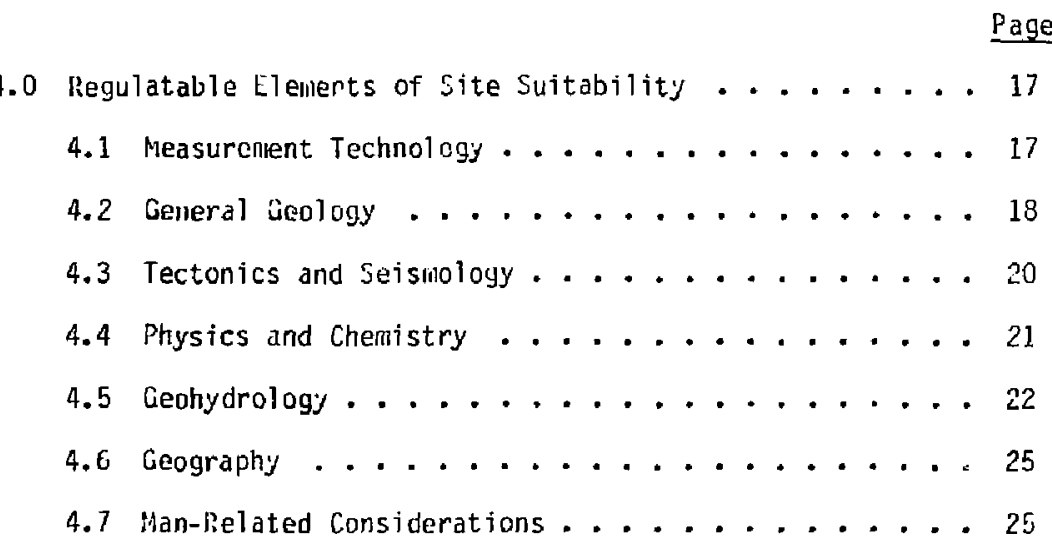

5.0 Regulatable [lements of Hodeling and Decision Analysis. - 27

5.1 Inductive hlethodology ............ 27

5.2 Deductive ilethodology ............. 28 


\section{LINTRODUCTIUN}

The Nuclear Regulatory Commission (NRC) is responsible for regulating the management and disposal of muclear wastes from licensej facilities.

The Lawrence Livermore Laboratory (LLL) is providing technical assistance to help the IraC develop standards for the lilanagement and disposal of high-level and transuranic wastes in deep geological repositories. The objectives of the LLL program are to provide an information base and a inethodology for developing standards for (1) waste form performance, (2) repository site suitability, and (3) repository design performance.

Regulations governing the handling and disposal of high-level nuclear wastes are drafted with the general purpose of preventing hazards to the health and safety of the human population. This basic theme is enunciatec in the statutes which authorize the IRC to pronilgate these regulations. Hazards are considered without specific limitations, and therefore, it is the task of tine drafters of regulations to delineate the extent of the regulatory protection. The basic policy for protection of the public health and safety litust be seen in the perspective of the economic, time, and resource limitations of society. In the case of the nuclear reactor regulations (10CF 250$)$, a balance has been achieved in the ALARR* concept.

*ALARA is defined as: "as low as reasonably achievable taking into account the state of technology, and the economics of improvement in relation to benefits to the public health and safety, and other societal socioeconomic consideration:" (10 CRF Section 50.34a). 
Deceniber 26, 1979

This report provides a basis for specifying those factors of a deep geological nuclear waste isolation system which should be regulated in any rational schelie for protection.

The report is organized into five sections. The first section identifies the scope and extent of the required regulations. In Sections 2 and 3, regulatable elenients are listed and described, for short-terin and lony-term performances of the waste foril and repositary design parts of the waste isolation systeil. Section 4 deals with geologic and hydrologic elenents. Regulatable elements of measurement techniques are described, and considerations that must be included in the site selction process are identified. Section 5 is a discussion of the regulatable elenents of the radeling and decision analysis process. 


\section{$1.0 \quad \underline{G o a l s}$}

The regulations for the nuclear waste isolation system must be consistent with two distinct goals:

1. The health and safety of workers and of the general public nilust be protected during all phases of storage and operation of the disposal facility. The period for this short term is defined as the time up to the decommissioning of the repository.

2. The health and safety of the population must be protected following decomissioning (long-term) of the disposal facility. Post.-sealing Inonitoring is desired for as long as adminstrative control over the repository can be inaintained. Decomissioning of a waste disposal facility lieans losing active control of the waste storage process. Protection of public health and safety under these conditions requires (i) measurement and analysis of the perfomance of the repository, (ii) assurance of thoroughness and accuracy of the lileasurements and analysis, and (iii) determination of the standards required for such perforinance.

The goals are to be achieved by enforcentent of regulations. The regulations must be based on regulatable elenents of a deep geological nuclear waste isolation systen. Regulatable elements are those characteristics of a candidate nuclear waste isolation sjstem which need to be specifjed to achieve control of the ultimate performance of the systell. These characteristics must be observable, yuantifiable and controllable. Most geological and hydrological elements, while uncontrollabie thenselves, must be considerations in the regulatable site selection process. 


\subsection{Regulatable [lements of Waste Form Performance}

\section{$2.1 \quad$ Waste Form}

Nuclear wastes which require deep geologic isolation can be in different furns. lligh level reprocessed waste may exist, for example, as finely divided oxides, as glass monolith, pellets, or as synroc. Unreprocessed spent fuel alay be placed in the canister in its original assembly, disasseribled, or chopped into sinall pieces.

Huclear waste should be in a non-dispersible fornil selected for chemical and thermal stability and low water solubility. Regulatable characteristics of waste form are described below.

\subsection{Short-term Performance}

1. Dispersibility. If the nuclear waste form is generated as finely divided particulate material, it should be further processed into non-dispersible form, i.e., pellets. Particle sizes smatler than 10 laicrons present a serious health hazard since they can becone dirborne and enter lungs through inhalation.

2. Chemical stability. The waste forli should not decollpose spontaneously or under the influence of radiation (radialysis). It should not readily react with water, air, rock, or engineering materials. Chemical stability of the waste form can be evaluated from thermodymanic considerations.

3. Thermal stability. Waste form should be a solid under the temperature conditions anticipated in the eriplacement environnent. It should not interact corrosively with the canister material and should have a low vapor pressure at expected temperatures, to preclude pressure build-up in the canister. 
4. Solubility. Waste form shouid have low solubility in water to uninimize potential spread of contarination in the event of an accident where water is involverl. Accident situations where direct water contact is possible include cases of canister rupture followed by fire (which would be fought with water), or a ruptured canister falling into a body of surface water.

\section{1 .2 Long Tern Perforliance}

1. Dispersibility. Huclear waste as finely divided oxides can be physically transported by yroundwater as a suspension. The aggregate surface area of the finely divided particles is large. If a process is surface area dependent, as dissolution or leaching might be, its rate can be accelerated. Wiste form should therefore be processed into densely compacted form.

2. Chemical stability. Haste form should not spontaneously decanpose and shrutd be stable to ionizing radiatici. It should have limited chemical reactivity in its enviromments.

3. Thermal stability. Waste form should be in the solid state under all predictable temperature conditions after repository decomissioning. It slould have low vapor pressure to preclude pressure buid-up in the canister in the event of accidental teniperature excursions.

4. Solubility. Haste form should exhibit low groundwater solubility which will jrolong the dissolution/leaching process and minimize the rate of yroundwater transport of the radionuclides to the biosphere.

5. Synergisın. A second waste form which will affect the solubility of the first waste form in a synergistic manner should not be placed in the same repository. Combinations of chemicals wich will adversely 
affect the geochemical retardation of radionuclide transport in the mediutn should be avoided.

\subsection{Canister}

The canister is the primary bartier against the release of radianuclides to the environient during the pre-emplacenient period. In the postemplacentent period, it is the sc...und birrier ayainst groundwater attack. The regulatable characteristics of the canister are described beiow.

\subsubsection{Short-term Perforliance}

1. Haterial of construction. The primary failure inode of the emplaced canister is corrosion. The canister material should be selected to perforin in the emplacelient environilent and to rellain intact and retrievable for the tine that retrievabijity nust be maintained.

2. Kechanjcal integrity. Since the canister is the primary barrier aydinst radionuclide release during pre-elnplacement, it should be designed to survive accidental drops during routine emplacentent operations and the stresses of retrieval operations.

3. Design considerations. Since the corrosion processes are strongly temperature dependent, the temperature at the canister surface should be controlled bihen in the emplacenent: mediun. Teliperature and thermal flux can be controlled by limit ing the anlount of nuclear waste through canister design and by sfacifying the age of the waste. Criticality accidents can also be precluded through canister design.

\subsubsection{Long-term Performance}

1. Haterial of construction. The canister is the seconc in the series of engineered barriers aydinst yroundwater contact with nuclear 
December 20, 1979

H.H 79-445-D

$-7$.

waste. The material should resist cormosion to provide protection against ground water intrusion.

2. Synergism. The synergistic effect of the corrosion products of the canister liaterial on the dissclution of the nuclear waste form should be considered. The corrosion products should not adverseiy affect the geochelincal retardation of radionuclide transport in the mediun.

3. Design corisiderations. Canister design should limit the nuclear waste content to control the surface temperature of the canister when placed in the emplacement environment.

\subsection{Packaging}

Packaying refers to the asse', slage of engineered barriers emplaced in the repository mediun for the isolation of nuclear waste from the biosphere. Packaging is the most infortant enyineered barrier ayainst ground water intrusion. It snould be designed to provide protection against the emplacement environment. Sesides resisting the corrosive attack of the groundwater, the packaying must support the lithostatic overburien and the themal stresses resulting from the heat generated in the nuclear waste assembly. The regulatable characteristics of packaging are described below.

\subsubsection{Short-Term Performance}

1. Corrosion. Packagin, material should be selected to perfortn in the emplacemeni environment over the period of retrievability and to provide a barrier against groundwater intrusion.

2. Hechanical integrity. Mechanical strength of the emplaced package will deteriorate due to corrosion. The waste package should be 
designed to allow successful retrieval of the canister and not collapse around the canister during the period then the retrievability option may be exercised.

? Design considerations. Package surface temperature must be controlled since corrosion rate is strongly temperature dependent. The temperature and the resultant therilal stress in the medium during normal repository operations must be controlled through the package design.

\subsubsection{Long-terin Performance}

1. Radionuclide transport retardation. The long-term performance is measured by the ability of the emplaced package to retain the radionuclides or to limit the rate of release. Selection of materials such as zeolites for packaging material should be required, to serve this purpose.

2. Corrosion. In the selection of the packaging materials we should exclude material combinations that will enhance the corrosion rate of one or more of the interials through electrolytic action.

3. Synergism. The corrosion products of the packaging material should not adversely affect the geochenical retardation of the radionuclide transport in the medium, nor should they synergistically affect the dissolution of the waste form in the groundwater.

\section{$2.4 \quad$ Manitoring Reguirements}

Continuous surveillance of waste package and the repository following the emplacenlent of the nuclear waste in its canister serves several purposes: radioactive safety, retrievability, and validation of package condition 
Deceituer 26, 1979

Will 73-445-D

-9 -

modeling for both short- and long-term prediction. A neasured low radiuactivity level in the repository will mean a satisfactory package performance and, inore important, a safe occupational environilent. Data such as temperature, thermal gradient, electrical conductivity, stress level, and strain rate on both the package and the repository can be analyzed to assess our predictive model of packaģe condition and bachagei illedium interaction for near-terli and validate theri for use in long-term prediction. Data from monitoring will a!so verify conister retrievability. The reculatable characteristics of monitoring are described below.

\subsubsection{Short-terill Perforinance}

1. Radiation level. A continuous radiological monitoring should be performed to assure a safe work environment for the operating personnel and to protect the health and safety of the general public.

2. Temperature/thermal gradient. The surface temperature of the canister/ package should be monitored, since corrosion rate is strongly temperature dependent. Information on tile thermal gradient is required for the assessment of thernal stress and brine higration problems.

3. Package movement. Successful retrieval of an emplaced package in bedded salt or doned salt requires precise positioning of retricval ilachinery with respect to the package. Due to lithostatic stress, the effect of brine inigration, or gravity, the package may change its position or orie-tation with tirlle. The package position and orientation should be monitored periodically to ensure retrievability.

4. Corrosion. The mechanical strength of an emplaced package will deteriorate with time due to corrosion. Corrosion rate is deterinined 
by the temperature and by the chenical characteristics of the groundwater. The properties of the groundwater that should be measured include hydrogen ion activity (pH), oxidation potential (Eh), and the concentration of the ionic species.

\subsubsection{Long-teril Performance}

1. Dissolution. The release rate of the radionuclides is deterinined by the temperature and by the chemical characteristics of the groundwater. The groundwater $\mathrm{pl}, \mathrm{Eh}$, and composition should be monitored for information about post-closure performance.

2. Syneryism. The dissolution (leaching) rate of the waste foriin nilay be synergistically affected by the presence of certain ions in the groundwater. Special effort should be made to determine their presence and the concentration level for corrective action prior to repository closure. 


\subsection{Regulatable [Tements of Repository Design Performance}

\subsection{Repository Structure and Operation}

\section{1 .1 Short-term Performance}

The following regulatable elements are related to the structural performance of the repository during the period before decomissioning and to the short-teril perforlildnce associated with the operation of the repository. in) regulations should comply with OSlih ard IISlin standards. Radiation exposure to operating personnel and to public should comply with 10CFI:20.

1. Waste lleat Loadiny. The waste heat loading should be such that the rock thermomechanical behavior does not prevent retrieval or induce large scale failure of mined openings or overlying strata.

2. Ventilation. The ventilation system should be able to perform the necessary air and heat transfer functions as construction proceeds without spreading accidental airborne radioactivity. The ventilation systen should have eniergency power. It should con'rol the flow of effluents off-site.

3. Repository Layout. several aspects, such as ventilation, structural integrity, and secure surface facilities, must be satisfied simultaneously. The trade-offs must be recognized and arialyzed. The number of shafts, shaft placement, and the number of levels in the repository are included in repository layout. The layout should be adaptable to account for unforeseen variations in site gealogy discovered in the mining process.

4. Drift Dimensions and Spacings. Conservative practices are required to achieve an adequate safety factor in the stability of the repository. 
5. Contingency Planning for Anomalies. The operator must consider all credible events, form contingency plans, and demonstrate ability to carry out contingency plans. In particular, plans for gas or water intrusion and rock burst must be considered. There must be procedures for cleanup after an accident.

6. Floor Loading. The weight and frequency of traffic can resuit in damage to floors that coldd prevent retrieval.

7. Seismic Vibration Response. It is not expected that a seismic event would damage the repository, but the reliability of the commuication link with the surface should be regulated, and the effect of seisilic motions on shafts and shaft seals considered.

8. Hined Rock liandling. From an enviromiental standpoint, the storage and disposal of misled rock should be regulated.

9. In-Situ Monitoring. It will be necessary to instrument the repository for lionitoring stridctural stability and respense to filining operations. Undesirable trends would necessitate corrective action.

10. Surface Facilities and Operations. The surface facjlities and operations should obey all regulations applicable to fuel cycle

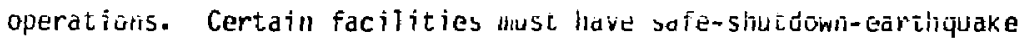
and safe-shutdown-power outage capabilities. Among these facilities are radiation handing facilities, shafts, and filter houses.

11. Radwaste Disposal systems. The treatment of radioactive waste generated on-site should be handled locally with limited effluent.

12. Haste Types and Mixtures. Different waste forms and types recuire different equjpment and procedures and present different hazards. For example, TRU waste in 55 gallon drunis could pose a fire hazard. It is preferable to segregate operations. 
13. Concurrence of Construction and Emplacement. Repository construction and waste emplacement at the same time creates operational problems for the filters and ventilation systens and makes jossible the interaction of the risks of both operations. I Jeneral, air strealis used for the cooling of radioactive waste should not be used for other ventilation needs.

14. Shaft Conveyances. The shaft for high-level waste and for the men and material shaft must be separate, have emergency power, limited drop, no hang-up, and be coripeterit to witlistand a design basis seismic event.

15. Waste liandling [quipment and Procedures. These should be designed to linit exposure to personnel. The design, including contingency plans for failures due to equipment or human factors, should be regulated.

16. Iraffic Control of Subsurface Velsicles. Extersive novement of men and material will occur in the repository. This is a local transportation problem with the usual risks that must be controlled by the usual regulations. The traffic route for waste nust be separate from the traffic route of men and material.

17. Dewatering Requirements. The ability to punp out excess vater duriny the operational phase aird any water encountered in the sining process must exist within the repository. storage of contaminated water nust be jrovided.

18. Criticality Control. The design must prevent criticality accidents under all credible scenarios.

19. Fire Control. The operator should have equipment and trained personnel necessary for fighting fires. 
20. Power Systens. Backup, noninterruptable power systems are needed for systems important for health and safety from the standpoint of waste.

21. Emplacement and Retrieval Mechanisms. These should be designed to be compatible witn each other. They should be designed to limii exposure to personnel and should cause no damage to the waste forll package.

22. Emplacement Methods and Sequence. [mplacement methods and sequence shouid isolate emplaced waste froin current and future activities.

23. Special Nuclear Material (SNM) Control and Accountability. A material control and accounting system will be required to assure that unauthorized access or removal is prevented.

24. Retrieval Capability. The ability to retrieve all emplaced waste and move it to the surface must be demonstrated. This includes the ability to make accommodations for safe surface storage in a timely manner or to transport the waste away from the site.

\subsubsection{Long-term Performance}

Some elements of structural performance impact on the long-teris perforinance of the repository.

1. Subsidence. Structural collapse could propagate fractures away froin the repository with adverse effects on ayuifers and seals. This could also accelerate waste migration. Regulations are required on the mine design to limit this effect.

2. waste Heat Loading. The thernomechanical response of the medium could produce new hydrological flow paths and enhance existing 
December 26, 1979 Wir 79-445-D

hydrological flow paths. The waste heat loading must be regulated to limit the thernomechanical rosponse.

\subsection{Repository Containment}

The following regulatable elements control long-teril risks related to repository containment performance.

1. Engineering for Decommissioning. The repository and its elements should be designed to allow safe, efficient decomissioning of the repository. The plan should be worked out in detail before construction starts and updated as mining proceeds.

2. Effect of Mining on Hydrological Parameters. Excavation techniques that do not induce fracture flow paths should be used in mining the repository.

3. Engineered Barriers. The repository should include engineered barriers that keep the waste package dry as long as practical and then limit the transport of radionulcides from the repository.

4. Repository Layout. The geometry of the repository should be regulated to preserve a waste-free zone near the shaft.

5. Shaft and Borehole Seals. Seals should be designed using demonstrated, modelable techsiques. The techniques may vary with rock type and site geology.

6. Backfill: Materials, Methods and Timing. Backfill affects transport properties, recharge time, thermal conduction, and structural stability. Backfill materials, methods, and timing must be regulated to limit these aspects appropriately. 
Decenber 26, 1979

WA 79-445-D

$-16$.

7. Validation of Predictions Prior to Decommissioning. Since safe performance of the repository is to be judged on the basis of predictions generated by models, the models should bo validated with data obtained during the operational period, wherever possible. 
December 25, 1979

Wir 79-445-D

\subsection{Regulatable Elenents of Site Suitability}

The selection process for identifying a suitable site for a nuclear waste isolation system can be regulated. The measurement techniques can be regulated to provide accurate information for that process. Although the geology and hydrology of the site cannot be controlled, certain geologic and hydrologic features must be considered in the selection process. In Section 4.1 , we ident ify the regulatable elements of the measurement technology. In Sections 4.2 through 4.7 , we describe the geologic and hydrologic considerations required for the selection process.

\subsection{Measurement Tecinotogy}

1. Data-type Requirements. The tyjes of information needed or site evaluation during the licensing procedure nust be specified.

2. Precision and Accuracy. The degree to which each required datum must lue determined should be specified. This specification may be superceded by specifications of measurenent technology, procedures, density, and quality control.

3. Instrunentation. It is necessar's to specify acceptable instrumentation and techniques to ensure that needed information is collected acceptably.

4. Data Collection Procedures. The quality of some measurements is dependent on the procedure used to perforn the measurement. Procedures must be specified in these cases. 
5. Measurement Density. The location and density of tests, especially borings, must be controlled to ensure that while the site is described adequately, site integrity is maintained.

6. Quality Control. Procedures necessary to ensure the quality and reliability of the data must be specified.

7. Data Interpretation Models. The procedures by which data are converted to model parameters should be specified. The interpretation of some information (especially field information) relies on professional judgrent and can be evaluated only by peer review.

8. Environmental Monitoring. During operations at a repository site, ongoing measurements must be nade to monitor the effect of those operations on the environment. This requires that baseline measureinents of environmental parameters be made before the start of operations of any type at the site. Environmental monitoring may include indrological information from wells in the region of the site, geophysical logs of boreholes in the site area, surface leveling surveys of the site, and surface air, water, and soil composition. Hany of these items should be measured pericdically during the operation of the repository and some for a period after decomissioning.

\subsection{General Geology}

1. Depth of Repository Layer. The repository layer should be deep enough to preclude the possibility of breach by surficial erosion or 
other surficial activities. The maximun depth will be limited by rock mechanical constraints.

2. Lateral Extent. The repository layer and surrounding layers should be continuous over sufficient latera! area to ensure that emplaced waste will be sufficiently isolated from surrounding aquifers.

3. Thickness. The repository layer should be thick enough to ensure the integrity of the repository as a barrier to waste migration.

4. Structure. The structure of the site area and region should be sufficiently understood so that performance modeling may be applied. Areas of complex folding and/or faulting must have a positive or ininimal neyative effect on waste migration.

5. Hatural Resource Potential. The site area should not contain constituents which in the foreseeable future may be economically desirable resources. These resources include hydrocarbons, industrial and strategic minerals, yroundwater, geothermal resources, and facilitics for underground storage. Areas should be avoided where any foreseeable exploration or exploitation activity could compromise the site.

6. Stratigraphic Seguence. Soluble repository layers such as bedded salt should be bounded above and belaw by aquitards such as tight shales, to minimize communication of the repository layer with. surrounding aquifers.

7. Geometry. In massive repository units, such as salt domes or granite bodies, it is important that the suirounding rocks be suitable aquitards or that the massive unit act as a deterrent to groundwater flow. 
Decenber 26, 1970

WM 79-445-D

\subsection{Tectonics ànd Seismalogy}

1. Iectonic Framekiork. The tactonic framework of a site should be evaluated. It is an indication of the complexity of the site and of the potential for future events that may disrupt the site, such as faulting and volcanic activity. Included in the tectonic framework are tectonic style and the ages of various tectonic events that have affected the region.

2. Fracturing. Thin jnints and fractures in the repo.:' $j$ liedium and rocks surrounding it may provide a flow path for groundwater and should be considered in site selection.

3. Faulting. Faults may provide interconnections between the repository layer and aquifers and they may interconnect aquifers in a manner that would adversely affect isolation.

4. Earthg!ake Potential. The potential for active faulting at the site must be evaluated. Actual displacements through the repository or new interconnections between aquifers or between aquifers and the surface would adversely affect isolation.

5. Diapirisrie Active diapiric movements in salt could affect isolation of waste. Domes proved to be undergoing movement at present should be excluded. Sites in salt domes should not be where these movements nitght be induced by thermal Toading of the waste. The question of ongoing diapirism in salt domes is a significant uncertainty at the present time.

6. Volcanisnl. Sites in rock such as tuff, basalt, or granite should be located to avoid potential volcanic activity. The age of volcanic 
December 26, 1979

activity at or near a site may be a tool for predicting future volcanism.

\section{4 ihysics and Chenistry}

1. Rock Composition. The chemical and inineralogical composition of the host rock and surrounding rocks will strongly influrence the radionuclide retardation characteristics of the various units.

2. Groundwater Composition. The chemical composition of groundwator is very important to the stability of the waste package and to radiomuclide transport. The important factors include oxidation potential (Eh), acidity $(\mathrm{pH})$, conductivity, and inorganic and organic species. Many of these factors must be determined in situ.

3. Groundwater Age. The age of groundwater in or near the repository layer will indicate the rate of potential radionuclide transuort in the region around the repository and will aid in deducing the hydroloc vistory of the area.

4. Mechanical Propertjes (applicable to both short-term and long-term performance): These rock properties will determine the ability of the repository and surrounding layers to support the openings of shafts and the repository cavity. Included here are strength, plasticity, and the various moduli.

5. Therma] Properties. These rock propertjes determine the response of the medium: to the thermal stresses presented by the waste. Conductivity, expansion coefficient and thermal alteration are important.

6. Retardation Potential. The capacity of the various rock units of the site, especially the aquifers, to retard by adsorption radionuclides 
December 26, 1979 WM 79-445-D

carried in groundwater is a cal part of the isolation system. In situ ineasurement of retardation potential and permeability is essential.

7. Radiation Effects. It is important that the detrinental effects of radiation on the chemical, mechanical and thermal properties of the repository nedium be known and accounted for.

8. Geothermal Gradient. For lang-term performance, the natural increase in temperature with depth at the site must not be such that the additional heat generated by the emplaced waste could present a problem to containment. In the short term, the natural temperature must be low enough that proper ventilation for mining and eriplacernent operations is possible.

9. Dissolution. The repository layer (in the vicinity of the repository) must be secure from dissolution by groundwater during the isolation period. In addition, conditions must be avoided which might lead to breccia pipe or rubble layer formation, such as inadequately sealed boreholes or shafts. These problems are significant in bedded and domed salt repositories.

10. Alteration. Chemical alteration of rock along fractures, especially igneous rack such as basalt and granite, may alter the retardation capability of those rocks, and may also affect the flow of groundwater in those fractures.

4.5 Geohydrology

1. Repository Medium Hydrologic Characteristics. To contain radionuclides properly, the repository layer should be a significant barrier to fluid flow. A low perueability in the repository medjum 
is necessary and, to be able to model long terin effects, a knowledge of the porosity and dispersivity is essential.

2. Hydrologic Characteristics of Surrounding Rocks. In many sites, especially those in layered rock, containment is enhanced by the low permeability of the surrounding media. To model the system adequateIy, the hydrologic characteristics of these rocks must be understood.

3. Hydraulic Gradients, Regional and Local. Fluid movement away from a repository is controlled by hydraulic gradients. These should be of a magnitude and direction that will limit migration of radionuclides to the bioshpere. Local gradient information is necessary for determining fluid movenent in and out of the repository. Regional gradient information is necessary to determine direction and rate of movenent to the potential water use locations.

4. Recharge and Discharge Rates and Locations. To understand the hydrology of the basin and of the repository site, the location of the recharge areas and rates mist be known. To provide a pathway of sufficient length to adequately delay the movement of radionuclides to the biosphere, the discharge areas must be at a sufficient distance from the repository and the discharge rate must be sufficiently low.

5. Depth to Water Table. The location and fluctuation of the water table over time is especially significant for sites initially above the water table.

6. Aquifer Capacity. The useable sapacity of the aquifers affects both the rate of radionuclide migration and the potential of the aquifer for groundwater withdrawal. 
December 26, 1979

WM 79-445-D

7. Hydrological Transients. Many hydrological systems have not reached a steady state. They are still showing the effects of past climatic conditions. These effects must be understood to model future radionuclide migration.

8. Present and Projected Climate. Some understanding of the present and future climatic conditions is necessary to wodel the hydrology. Additional effort to understand the long term relationship between climate and hydrology may be necessary at some sites climate variation may cause cilanges in hydraulic gradients at or near the site.

9. Surface Hydrology. Surface hydrology and its potential modification are essential parts of the hydrologic model. The region's potential for flooding naturally or by man-made impoundments should be evaluated. Natural streas pasition changes wich might alter the pathway from the repository to the biosphere should also be projected and evaluated.

10. Flow Characteristics. It is necessary to understand the type of flow through all of the rock units involved in the hydrologic model. Rocks like granite and basalt will exhibit fracture flow while tuff and shale may involve porous flow as well.

11. Interbed Characteristics. In bedded rocks like salt, there are often interbedded litaterials that have an adverse effect on the repository. Interbeds may provide a pathway by wich water may enter or leave the repository. These must be evaluated to determine their impact on the performance of the repository. 
Decenber 26, 1979

\subsection{Geography}

I. Site Ownership. The repository should be located at a site where the federal goverment has control over the surface and the subsurface over a substantial area.

2. Demography. Areas of current or projected high population density should be avoided.

\subsection{Man-related Considerations}

1. Borehole Density. Open or poorly sealed boreholes may provide fluid connections between aquifers or between the repository Iayer and an aquifer. This should be minimized by careful plugging of existing holes and drilling only a limited number of holes at or rear the repository site. The existing borehole density is an important factor in site selection. A carefil search for pre-existing boreholes is necessary.

2. Aquifer Use. Hydraulic gradients and fluid velocities increase when water is extracted from ayuifers. Injection of fluids into açuifers will also alter hydraulic characteristics. The use or potential for use of aquifers in the area of concern near a repository should be limited.

3. Underground Activities. Disturbance of the sub-surface by mining, fluid production, disposal or storage may affect the containment capability of the strata containing or surrounding a repository. Past and present activities of this type in the area should be limited and the potential for future development should be small. 
December 26, 1979 WM 79-445-D

4. Solution Mining. Some econonic ninerals are obtained by solution mining (salt, uranium and sulphur are examples). This activity could affect repository integrity and should be limited in the area of the repository (past, present and future).

5. Hydrocarbon Storage. Some rock types are suitable for hydrocarbon storage. Cavities in salt and porous strata capped by impermeable layers are examples. This activity could affect repository integrity and the area near the site should have a limited potential for such use. 


\subsection{Regulatable Elements of Hodeling and Decision Analysis}

An analysis process is a tool for making decisions with inperfect information and many options for site seslection and repository design. The analysis process contains both inductive and deductive elements. The inductive elements involve mainly expert judgmental issues such as model selection, estimates of error, and process identification and selection. The deductive elerients involve the formal conclusions which can be dratun by use of models. Both inductive and deductive elements operating on an information base are used in the deternination of acceptable perfornance. The regulatable features of the analysis process are detailed below.

\subsection{Inductive Methodology}

1. Expert judgment. [xpert judgment will play a significant role in the assessrient of any site. Those areas in which expert judyment does play an important role must be clearly identified. Qualifications for experts must be clearly expressed.

2. Parameter estimation methodology. The estimation of model parameters from a set of ineasuriments is an important issue. The estimation process which contains both inductive and deductive elements must be clearly defined and regulated.

3. Rules of Inference. The rules by which performance is inferred from measurement must be stated and regulated. For example, regulations are required to expressly state under which conditions worst case analysis, uncertainty analysis and fault tree analysis are to be used and what limits must be piaced on their use. Techniques for the generation and analysis of scenarios inust also have guidelines. 
Decentser 26, 1979

HNi 79-445-D

$-28-$

\subsection{Deductive Hethodology}

1. Codes and Mode15. The codes used in the evaluation process must be validated, tested, and accepted. Validation testing and acceptance procedures inust be defined.

2. Performance Measure. The output format for conclusions must be clearly given. A uniform measure of repository performance must be agreed upon. Ranges of acceptable performance may then be specified. 